\title{
Terrazas en altura como oferta turística experiencial: el caso de Madrid
}

\section{Rooftop terraces as an experiential tourist offer: the case of Madrid (Spain) Frank Babinger \\ fbabinger@ucm.es @ 0000-0003-0372-1842}

Departamento de Geografía, Facultad de Comercio y Turismo. Universidad Complutense de Madrid. Avenida de Filipinas, 3. 28003 Madrid, España

\section{$M^{a}$ Milagros Serrano-Cambronero}

mserrano@ucm.es (10000-0002-4717-6834

Departamento de Geografía, Facultad de Geografía e Historia. Universidad Complutense de Madrid. Calle del Profesor Aranguren, s/n. 28040 Madrid, España

\section{INFO ARTÍCULO}

\section{Recibido: 24-05-2021}

Revisado: 14-06-2021

Aceptado: 21-06-2021

\section{PALABRAS CLAVE}

Turismo experiencial Terrazas hoteleras Recursos turísticos Consumo de paisaje Madrid

\section{KEYWORDS}

Experiential tourism

Hotel terraces

Tourist resources

Landscape consumption Madrid

\section{RESUMEN}

El presente artículo se centra en el análisis de las terrazas en altura de la ciudad de Madrid como ejemplo de las nuevas demandas turísticas en entornos urbanos. De esta manera destacan como muestra de oferta destinada a satisfacer las necesidades de los turistas posmodernos que piden experiencias turísticas de calidad.

La metodología se ha basado en primer lugar en una revisión bibliográfica, en segundo lugar, en la búsqueda de terrazas a través de páginas web especializadas y trabajo de campo, y su posterior georreferenciación, y por último en el análisis de la información.

Se presenta la distribución espacial de las mismas, a través de cartografía actualizada, realizada tras la georreferenciación de las terrazas.

Destaca que las terrazas en altura entroncan directamente con la oferta de turismo experiencial y de calidad demandada por los turistas, a la vez que su distribución geográfica muestra su clara relación con el área más turística de la ciudad de Madrid. 


\section{INTRODUCCIÓN}

Las ciudades constituyen, en la actualidad, un destino turístico prioritario debido a la gran concentración de actividades de ocio y consumo que se ofertan en ellas. El turismo se utiliza cada vez más como un recurso que permite transformar el sistema productivo de las ciudades y, en este sentido, muchas actividades turísticas se transforman, inventan o re-inventan continuamente, para que las ciudades puedan ser competitivas en un escenario global (Córdoba \& Gago, 2018).

Tal como señalan estos autores, la actividad turística es una práctica cultural en las ciudades, donde conviven y se entremezclan el turismo propiamente dicho, con las actividades de ocio de sus habitantes (Córdoba \& Gago, 2018).

En un mundo altamente competitivo, muchas ciudades turísticas se están reinterpretando a la vez que proceden a diversificar sus recursos conocidos de una manera diferente. Esta diversificación de la oferta turística, enmarcada en aquellas demandas por los turistas postmodernos, se basa en muchas ocasiones en la creación de lugares (Richards, 2020) y de nuevas experiencias para los visitantes. En este sentido emergen nuevos espacios turísticos que satisfacen las expectativas de los turistas en búsqueda de alternativas.

Enmarcados en esta dinámica, los hoteles, símbolo del turismo tradicional, se han reinventado y adaptado a una nueva demanda o creando nuevas ofertas turísticas para atraer a la misma (Babinger \& Serrano, 2020). En este contexto, una de las grandes tendencias actuales de los hoteles urbanos, y de otros edificios singulares de la ciudad, es la adaptación de su última planta o de la azotea para transformarlas en terrazas que atraen no solamente a los clientes del hotel, sino que son también una oferta de ocio de calidad para la población local (Serrano \& Babinger, 2021).

Las terrazas en altura de edificios singulares de las ciudades, en especial aquellas ubicadas en las azoteas de hoteles de centros urbanos neurálgicos, se han erigido en espacios privilegiados para el consumo del paisaje urbano. Este paisaje se convierte de esta manera en un recurso consumible a la vez por los turistas, como por los propios habitantes de la ciudad. En este sentido, se trata de poner a disposición del turismo, recursos anteriormente poco aprovechados (Gwiazdzinski, 2009).

Cabe precisar que el paisaje siempre ha formado parte de lo que espera encontrarse el turista en el destino turístico, sea rural, litoral o urbano. El consumo de este paisaje se ha convertido en algunos casos en motivación fundamental del viaje y forma parte de la esencia de la experiencia vivida. Aunque sea un tema a veces subjetivo, los paisajes atractivos son susceptibles de crear experiencias y de ser consumidos como oferta turística.

Aunque el paisaje forma parte intrínseca de la oferta turística de cualquier lugar, no se ha considerado como recurso turístico de igual manera que otros equipamientos (Nogué i Font, 1989). Esta realidad cobra especial importancia cuando se tienen en cuenta las diferentes instalaciones que se basan, precisamente, en el paisaje que se puede vislumbrar desde los mismos como miradores (Trivi, 2018) o plataformas de observación (Liu \& Dewancker, 2018). En este sentido, las terrazas en altura se convierten en plataformas destacadas para el consumo del paisaje urbano tanto por parte de los turistas que la visitan, como por la de los habitantes de la ciudad. Desde las mismas se oferta una nueva visión de un paisaje en principio conocido, pero que encierra una experiencia turística innovadora.

Los destinos de ciudad, para la actividad del turismo urbano, hoy día representan "la segunda opción favorita para los turistas, después de los viajes a la playa y suponen el $22 \%$ de los desplazamientos de placer en todo el mundo" (IEPPO, 2017). Este auge del turismo urbano se hace muy patente en muchas ciudades españolas entre ellas en la ciudad de Madrid, en la cual la actividad turística generó más de 9.500 millones de euros en 2016, lo que supone más del 7\% de su PIB (Hosteltur, 2015).

Este artículo combina estos aspectos -turismo urbano, paisaje, terrazas hoteleras y experiencia turística derivada de las mismas- en la ciudad de Madrid que, según la encuesta de Ocupación Hotelera (INE, 2019) recibió en 2018 9,7 millones de visitas. De esta manera constituye la primera ciudad del país en el número total de turistas, aunque no de visitantes extranjeros, posición dominada por la ciudad de Barcelona.

El objetivo general de este trabajo es el estudio de las terrazas en altura en la ciudad de Madrid, como ejemplo de las nuevas demandas turísticas en entornos urbanos y las necesidades de los turistas posmodernos de consumir la ciudad mediante experiencias turísticas de calidad. 
Un subobjetivo es analizar la distribución espacial de las terrazas hoteleras, frecuentemente de reciente creación, utilizando para ello cartografía actualizada de su localización.

\section{MARCO TEÓRICO}

La actividad turística es indudablemente una de las principales actividades económicas a escala mundial. El turismo incide directamente en el desarrollo de países, de regiones o de ciudades (Scheyvens, 2002; Sharpley Telfer, 2003), en función de la estructura económica de las mismas. En este sentido, y tal como señala Ashworth (1989), la actividad de los turistas se entremezcla con las de ocio de los propios residentes, en un marco de consumo de recursos compartidos.

A ello se añade que la actividad turística se ha transformado considerablemente en las últimas décadas, pasando de estar basada casi exclusivamente en modelos territoriales concretos -sol y playa, naturaleza, urbano, etc.- a otro basado en diferentes modalidades. Nos referimos al turismo sostenible, de calidad y experiencial, entre otros, que pueden ser aplicados indistintamente a diferentes destinos.

Esta evolución se enmarca, evidentemente, en la globalización que ha impulsado otros fenómenos culturales como el consumo de espacios (Zukin, 1995; Urry, 2002, 2010; Hanningan, 2005) y la espectacularización y artificialización de las prácticas sociales (Córdoba, 2009; Igoe, 2010; Córdoba \& Gago, 2018).

En este marco globalizado, las ciudades, también globales en palabras de Sassen (1991), constituyen espacios consumibles en todas sus vertientes (Mansvelt, 2008), incluyendo sus aspectos económicos, sociales y culturales. Esta realidad incluye movimientos de tematización y re-invención (Gago, Díez \& Córdoba, 2017; Gago \& Díez, 2020) para atraer a los turistas que se mueven en un mundo competitivo (Miles, 2012).

El turismo experiencial, que está estrechamente relacionado con la globalización, se ha erigido en representante de una nueva demanda turística postmoderna (Urry, 1995) basada en un turista hedonista en búsqueda de satisfacción personal que va más allá de su vida cotidiana (Córdoba \& Gago, 2018). Sin embargo, el concepto no es novedoso, puesto que hace casi 25 años que Thrift (1997) hablaba ya de una "economía de experiencia", mientras que otros autores han defendido que más que productos, realmente se vendían experiencias en los destinos turísticos (Vogeler \& Hernández, 2002; Rivera, 2013).

Por lo tanto, se puede decir que el concepto de turismo experiencial empezó a fraguarse a finales de los años noventa del siglo pasado y al inicio del actual mientras que se erigió rápidamente como tendencia turística a tener en cuenta (Smith, 2006).

La experiencia buscada por el turista significa encontrar una vivencia diferenciada de su vida cotidiana y entronca con lo que otros han denominado "turismo emocional" (García \& Salvaj, 2017), que pretende cautivar al turista (Rivera Mateos, 2013).

La creciente búsqueda de experiencias (Gilmore \& Pine, 2002), y de su consumo por parte del turista, le lleva a buscar emular la actividad de los residentes de los destinos que visita, especialmente en las ciudades globalizadas. De esta manera pretende participar en la vida cotidiana de la población (Fernández, 2010), obteniendo una "experiencia total" (De Rojas \& Camarero, 2008) enmarcada en la "economía de la experiencia" (Pine \& Gilmore, 1999).

Richards, que ha tratado extensamente el tema del turismo experiencial desde el paradigma del turismo creativo $(2004,2011,2020)$, demuestra que el éxito de la oferta experiencial está directamente relacionado con su especificidad, diferenciándose de otros destinos y actividades. Tal como señala García (2017), “No es lo mismo visitar un destino que sentir un destino (olores, colores, gusto, texturas...) y vivir un destino con sus habitantes."

Como resultado, el turismo experiencial está en continuo crecimiento, constituyendo una vivencia personal (Rivera, 2013) y permitiendo al turista convertirse en protagonista de su propia experiencia turística en el destino (García, 2018). Además, hay que tener en cuenta que para el turista postmoderno la experiencia turística constituye un fin en sí mismo (Quaglieri \& Russo, 2010).

La propia Organización Mundial del Turismo (2020) se hace eco de la tendencia del turismo experiencial que incluyen, entre otros, el espectáculo y la emoción (García, 2018). Igualmente, según explica Rivera (2013), 
el plan estratégico del turismo de España, Plan Horizonte 2020 incluía las experiencias turísticas como eje principal para la creación de valor de los destinos turísticos.

Por lo tanto, podemos señalar que las nuevas tendencias turísticas dan una cada vez mayor importancia a las expectativas de los turistas. A su vez, los turistas experienciales conceden cada vez un mayor peso a su participación en la cultura y los hábitos locales en el destino. Debido a ello, la oferta turística está evolucionando de un modelo estático a otro dinámico que incluye aspectos de co-creación de espacios (Richards, 2020) entre la oferta de los destinos y los turistas (García, 2018). Por ello, la elaboración de una nueva oferta adaptada y la (co-)creación de nuevos espacios turísticos que responden a la necesidad de los turistas es una necesidad para muchos destinos que quieren diversificar su oferta.

En este sentido, habría que mencionar que se enmarca en la importancia de hacer partícipe a la población local, mientras que permite la transición del turista pasivo y observador, a activo y participativo de la vida en el destino. Tal como señala García (2018), la población local está cada vez más consciente de la importancia del turismo en su ciudad y, a la vez, de su forma de vida para el turismo. Lo que conlleva una mayor implicación de la misma en los procesos de co-creación turística.

Relacionada con este turismo de experiencia se presenta la transformación urbana en la que se remodelan y reinventan lugares y actividades (Córdoba \& Gago, 2018) que se ponen a disposición del turista y del ocio de los residentes, como las terrazas en altura.

Esta idea y aun no siendo el objetivo de nuestra investigación, podría enlazar con el denominado turismo de proximidad, que supone poner en un primer plano ciertos valores que son (re)descubiertos a partir de una actividad turística y que terminan formando parte del territorio reforzando a su vez su identidad en un contexto altamente competitivo (Díaz \& Llurdés, 2013; Díaz, 2017).

\section{Terrazas en altura}

La atracción de los centros urbanos sigue en aumento y, en clave turística, éstos son constantemente transformadas para dar respuesta a los intereses económicos y el mantenimiento del sistema turístico-urbano (Da Rocha \& Furtado, 2018). Enmarcados en esta dinámica, los hoteles, símbolos del turismo en las ciudades antes de la llegada y del incremento de las viviendas turísticas, se han reinventado y adaptado a una nueva demanda o directamente han creado una nueva oferta para atraer a la misma. Para esta diversificación de la oferta turística, en parte basada en la oferta de nuevas experiencias para los visitantes que hemos comentado en el apartado anterior, emergen nuevos espacios turísticos que satisfacen las expectativas de los turistas en búsqueda de alternativas (García, 2018).

Al igual que la administración pública interviene directamente en la transformación turística de las ciudades hacia una mayor espectacularización (Da Rocha \& Furtado 2018), las empresas privadas actúan al unísono en los espacios que son de su competencia. Las actividades turísticas y de ocio concentran a la vez inversión y rentabilidad (Lefebvre, 2013), mientras que las empresas hoteleras son sus máximos representantes. La inversión en nuevas construcciones, y las mejoras en las existentes, son una realidad constante en este sector, marcado, también, por la rentabilidad de estas actuaciones.

Así, los hoteles están siguiendo actualmente una paulatina transformación para adaptarse a los diferentes nichos existentes, y con una clara tendencia hacia una mayor calidad con hoteles boutique, o categorías de lujo y alta gama, como es el caso de la ciudad de Madrid. En este sentido una de las grandes tendencias actuales de los hoteles urbanos, es la adaptación de la última planta o de la azotea con terrazas que atraen no solamente a los clientes del hotel, sino que están abiertas al público en general.

Las terrazas en altura, como nueva oferta turística de calidad, se convierten en proveedoras de experiencias para un nicho de mercado creciente y deseoso de prácticas turísticas diferentes (García, 2018). Para ello recurren en gran parte al uso del recurso del paisaje, concretamente "la venta del paisaje urbano". De esta manera, este consumo turístico y de ocio del paisaje urbano se convierte en experiencia por parte de los consumidores o usuarios. Aunque este fenómeno no es exclusivo de los hoteles, se ha podido constatar que la mayoría de estos nuevos recursos turísticos experienciales se ubica mayoritariamente en estos establecimientos. 
Esta nueva oferta turística en espacios reconfigurados también tiene relación con la mayor importancia concedida al denominado turismo nocturno y la turistificación de la noche urbana (Giordano et al., 2018). Como mencionan estos autores, la oferta de actividades nocturnas de calidad se ha convertido en un elemento central de la competitividad turística de las grandes urbes. Esta constatación enlaza directamente con lo expuesto en el Plan Estratégico Madrid Destino 2015-2019, que enmarcaba las "rooftops" en el epígrafe "by night" (figura 1, Ayuntamiento de Madrid, 2014).

Además, en línea de lo comentado, la diferenciación clásica entre turismo externo y ocio local es aún más difusa que en las actividades turísticas habituales (Giordano et al., 2018) y las terrazas se ofrecen tanto a los turistas como a los residentes mientras que compiten por todo tipo de "cliente" (Murphy \& Boyle, 2006).

Adicionalmente, la situación actual provocada por el Covid-19 favorece aún más este tipo de oferta novedosa en espacios urbanos turísticos maduros por la necesidad de los turistas y residentes locales de evitar espacios cerrados y concurridos.

En tiempos de globalización y homogeneización de la oferta turística, los visitantes quieren disfrutar de una oferta especializada, más que de entornos "mono-culturales" (Castillo-Canalejo et al., 2020). En este sentido, las terrazas en altura permiten una visión diferente de una realidad conocida y amplían la oferta visual, sin tener que modificar la existente.

En su artículo sobre los mercados de Córdoba, las autoras mencionan que una de las motivaciones primordiales en su visita son el hedonismo y el ocio (Castillo-Canalejo et al., 2020). Concluyen que no pueden focalizar únicamente en la oferta gastronómica, sino que tienen que ofertar otro tipo de ocio y recreo, lo que sí cumplen las terrazas con sus vistas sobre la ciudad, además de la oferta complementaria que suelen ofrecer (conciertos, bebidas, comidas, etc.).

La oferta turística del paisaje consumido por los visitantes desde las terrazas en altura brinda una experiencia diferencial ansiada por el turista postmoderno. En este sentido, la oferta concuerda perfectamente con las expectativas creadas, que se pueden resumir en poder disfrutar del paisaje urbano desde otro punto de vista, satisfaciendo esta búsqueda de experiencias que se estaba comentando.

Tal como han demostrado Liu \& Dewancker (2018) en el caso de los observatorios, éstos muestran altos grados de satisfacción por parte de sus visitantes mientras que las terrazas en altura presentan además toda una serie de ofertas de ocio adicionales. La alta satisfacción tiene fácil explicación, ya que la oferta concuerda perfectamente con las expectativas, que se pueden reducir a tener unas bonitas vistas de la ciudad, en compañía, y disfrutando de una oferta gastronómica adicional.

Por ello podemos concluir que las inversiones recientes para incorporar las terrazas a la oferta turística y de ocio en las ciudades construyen nuevos espacios creados para satisfacer la expectación de los turistas y visitantes. En este sentido, esta aproximación sería la que los autores franceses denominan "la mise en tourisme" (Gwiazdzinski, 2009), la puesta a disposición del turismo de recursos anteriormente poco aprovechados. En este sentido, las terrazas hoteleras han pasado de ser un recurso tradicional de uso privativo para los huéspedes a convertirse en una nueva oferta turística experiencial y de calidad accesible para todos los visitantes.

Como hemos comentado anteriormente, el turismo experiencial se está consolidando en muchas ciudades como un activo de primer orden en relación con una demanda creciente de experiencias (Gilmore \& Pine, 2002) y con otras formas de consumo posfordista (Urry, 2002).

Las ciudades postmodernas adaptan su oferta turística tradicional a esta nueva demanda y los hoteles participan activamente en esta transformación. En este sentido, las terrazas hoteleras han pasado de ser un recurso ofertado de manera limitada a los huéspedes alojados, a convertirse en una nueva oferta turística accesible para todos los visitantes, de las cuales el paisaje urbano se vende como experiencia única. La demanda de experiencias, por lo tanto, está convirtiendo a las terrazas en altura en una parte esencial de la oferta turística de las ciudades del siglo XXI. La experiencia sensorial del turista, que mencionaba Schmitt (1999 y 2003), desarrolla aquí todo su sentido, mientras que la oferta se enmarca en el consumo de lugares, imágenes y experiencias, que tan bien describía Urry (2010).

La reciente evolución de la oferta turística de calidad de la ciudad de Madrid no está ajena a esta realidad, en la que en los últimos años se ha producido una ampliación de los recursos ofertados. En este sentido, se 
puede constatar que los hoteles se han adaptado y han incorporado las terrazas a su oferta de turismo y ocio poniéndolas a disposición de turistas y residentes.

Según el Ayuntamiento de Madrid (2019), la importancia de la ciudad como destino urbano se consolidó en 2019. El total de pernoctaciones superó los 22 millones y más del $60 \%$ fue generado por viajeros internacionales. Durante ese año, Madrid recibió un total de 10.419.709 viajeros, un 2,06 \% más que en 2018. De ellos, más de 5,5 millones (el 54,85 \%) fueron internacionales y generaron un gasto que superó los 10.451 millones de euros. "El carácter abierto y acogedor de la ciudad, su conectividad y accesibilidad, y la oferta cultural, gastronómica y de ocio son los principales motivos para que Madrid tenga un reconocimiento nacional e internacional entre la demanda turística" (Ayuntamiento de Madrid, 2019).

El anuario de Turismo del Ayuntamiento de Madrid (2019) apuesta por un "turismo de calidad y sostenible". En él señala que "el centro de Madrid está viviendo un proceso de reconversión hotelera y las grandes cadenas internacionales del segmento del lujo han apostado por estar presentes en el centro de la ciudad". Madrid debe avanzar hacia un modelo de crecimiento inspirado en la calidad y en la sostenibilidad, generando valor tanto para el visitante como para el ciudadano (Ayuntamiento de Madrid, 2019).

La apuesta por la calidad como línea estratégica del turismo es algo que ya aparecía como unos de los principios generales de la Estrategia de Turismo de la Comunidad de Madrid 2016-2019. En ella, se persigue "un turismo de calidad, generador de empleo y bienestar (...) para hacer de la Comunidad de Madrid uno de los grandes destinos del mundo, capaz de atraer un turismo de calidad que genere empleo y bienestar social" (Comunidad de Madrid, 2015).

El Plan Estratégico Madrid Destino 2015-2019 menciona específicamente las terrazas en altura en una de las 14 categorías de producto y de las 7 propuestas específicas. Las terrazas y “Rooftops" se incluían concretamente en la categoría "disfrutar by night" (figura 1), por lo que se pueden enmarcar en una apuesta estratégica no solamente de los hoteles, sino de la ciudad en su conjunto para una oferta de turismo y ocio exclusiva, experiencial y de calidad (Ayuntamiento de Madrid, 2014).

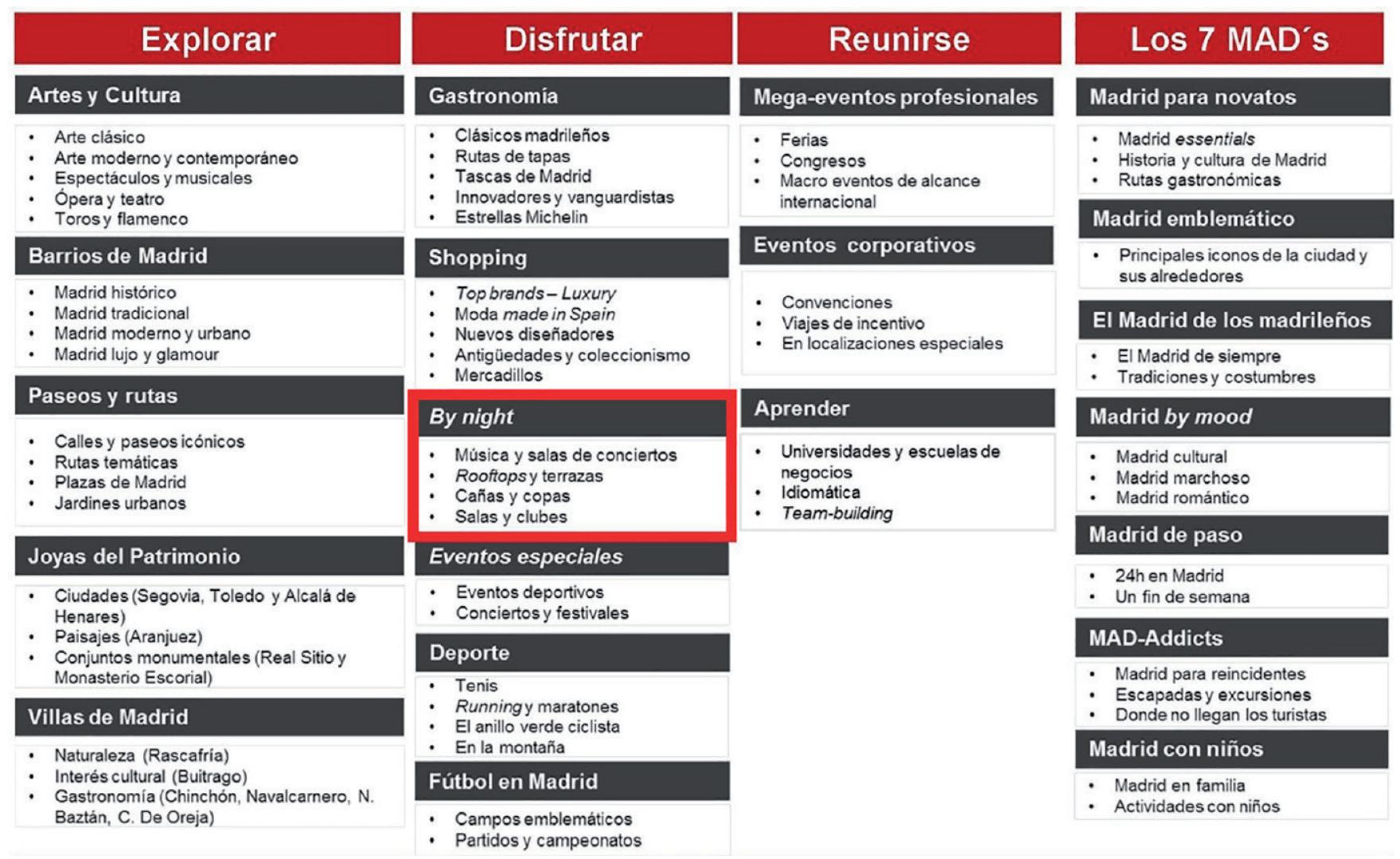

Figura 1. Categorías de producto y propuestas específicas para el turismo de Madrid. Fuente: Plan Estratégico Madrid Destino 2015-2019, Resumen ejecutivo, p.17. 


\section{METODOLOGÍA}

La propuesta metodológica para el desarrollo de la investigación se ha basado en la combinación de técnicas cuantitativas y cualitativas, que han permitido crear una base de datos georreferenciada de las terrazas en altura de los hoteles y de otros edificios singulares en la ciudad de Madrid, hasta ahora inexistente. Esta base de datos ha sido diseñada de tal manera que permite actualizar fácilmente cualquier nuevo espacio, (terraza en altura) que aparezca en la ciudad de Madrid, así como incorporar otro tipo de información (atributos) que sea necesaria para sucesivas investigaciones. Queremos destacar también que este diseño, podrá servir de ejemplo para estudios similares en otras ciudades españolas (Babinger \& Serrano, 2020).

En el proceso metodológico, pueden diferenciarse tres fases (ver figura 2):

\begin{tabular}{|c|}
\hline Fase 1 \\
Revisión bibliográfica y \\
teórica
\end{tabular}

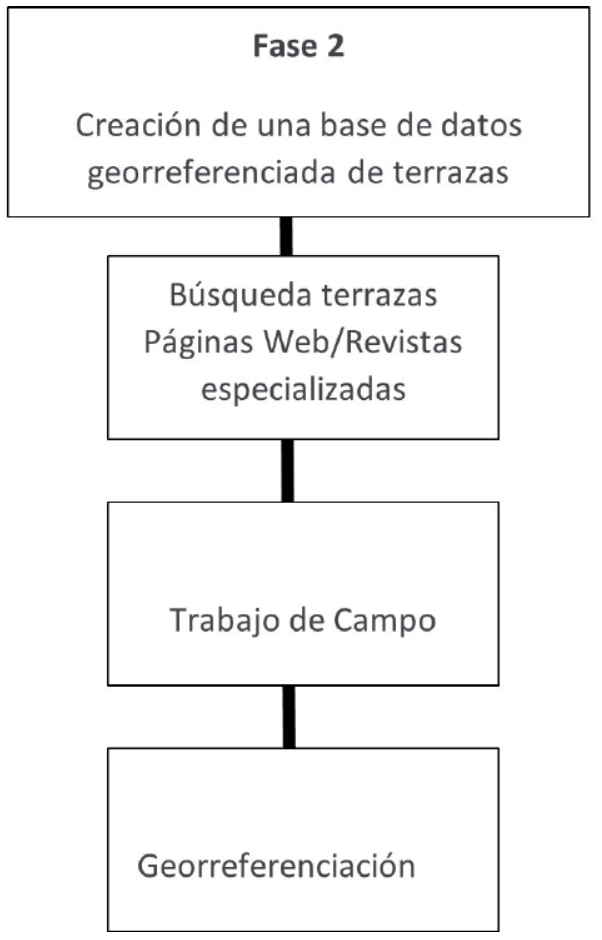

Figura 2. Esquema Metodológico. Fuente: Elaboración propia.

- PRIMERA FASE. Se llevó a cabo una exhaustiva revisión bibliográfica sobre el turismo experiencial y la creación de espacios turísticos de las ciudades, centrándose específicamente en el caso de la ciudad Madrid; en este sentido nos dimos cuenta de la inexistencia de estudios concretos sobre las terrazas en altura como ejemplo de turismo experiencial.

- SEGUNDA FASE. Búsqueda intensiva de las terrazas en altura abiertas al turismo y ocio en la ciudad de Madrid. Este proceso se llevó a cabo mediante la consulta de páginas web tanto especializadas en turismo, como en aquellas de difusión general. Son muchas las webs y los anuncios que promocionan y publicitan las terrazas en altura, sin embargo, muchas de ellas están incompletas y se limitan a mostrar únicamente las 10 o 20 más representativas. La consulta de todas ellas nos ha permitido identificar hasta la fecha un total de 41.

Una vez realizada la identificación de las terrazas, se procedió a comprobar la información recopilada in situ mediante un exhaustivo trabajo de campo.

Finalmente, con toda la información recogida, se diseñó una base de datos, la cual fue georreferenciada generándose un Sistema de Información Geográfica, mediante el software ARC GIS. Esta base de datos permite comprobar la distribución y ubicación de las terrazas hoteleras y su relación con la actividad turística en la ciudad de Madrid y sustentan la discusión y las conclusiones del presente 
trabajo. Esa base de datos como ya se ha mencionado, es abierta y se irá ampliando en la medida que avance la investigación sobre este tema en el futuro.

- TERCERA FASE. Una vez constituido el fundamento de la investigación, se profundizó con el análisis de la información contenida en las páginas web de los hoteles, haciendo especial hincapié en la publicidad de las terrazas.

Inicialmente, se propuso combinar las fases anteriores con entrevistas en profundidad con los responsables de los hoteles, como de los comentarios de los usuarios en plataformas conocidas (TripAdvisor, entre otras). Sin embargo, la práctica paralización de la actividad desde hace más de un año por la pandemia del COVID-19, y las limitaciones a la movilidad y las reuniones presenciales, solamente permitieron una entrevista inicial, en concreto al Director del Hotel Urban de Madrid. Por ello quedan pendientes para futuras investigaciones en marcha.

\section{RESULTADOS Y DISCUSIÓN}

El análisis de las terrazas en altura ofrecidas como reclamo turístico y de ocio ha mostrado, en primer lugar, una preponderancia clara de las terrazas hoteleras sobre otras terrazas ubicadas en espacios singulares de la ciudad de Madrid. Entre estos últimos podríamos citar a la Terraza Cibeles, en el edificio del mismo nombre y sede del Ayuntamiento de Madrid, la Azotea del Mercado Barceló o la Azotea del Círculo de Bellas Artes, entre otros.

De esta manera, más de dos tercios de las terrazas referenciadas en Madrid se ubican en hoteles, mientras algo menos del 32\% lo está en otro tipo de edificio. No obstante, cabe señalar que muchos de ellos guardan también una relación directa con la actividad turística y de ocio, como el Mercado de San Antón, la terraza del Casino, el Mirador del Museo Thyssen, el ABC Sky Bar, o los de El Corte Inglés de Callao o Serrano.

No obstante, es claramente en los hoteles en los que las terrazas cobran un significado especial relacionado con el turismo experiencial. Hasta tal punto que en algunos casos se convierten en el reclamo principal del hotel, destacado en la página de inicio, como ocurre, entre otros, en el caso del Room Mate Óscar (https://room-matehotels.com/es/oscar) o del novedoso Riu Plaza de España (www.riu.com/en/hotel/spain/ madrid/hotel-riu-plaza-espana). En todo caso, destaca que en prácticamente todos los casos se trata de hoteles de lujo o alta gama, destacando los de 4 y 5 estrellas, además de los hoteles boutique que están en auge en la actualidad. En esta línea destaca la reciente y futura apertura o renovación de hoteles de lujo en Madrid como el Four Seasons, el Ritz, el Palace o el futuro JW Marriott de la plaza Canalejas.

Por lo que se puede afirmar que las terrazas constituyen nuevos recursos de ocio de calidad en el centro turístico de la ciudad, enfocados a ofrecer nuevas experiencias a sus usuarios, sean éstos turistas o residentes.

Analizando las páginas web de los hoteles, se pueden encontrar muchas similitudes de lo que se promociona en las terrazas. Además de las vistas, que se comentarán a continuación y que reafirman la importancia de las mismas especificada por Liu \& Dewancker (2018), la mayoría destaca el aspecto de tratarse de espacios nuevos, renovados, remodelados, reconvertidos, recuperados o reinventados. Una realidad que entronca con lo que hemos destacado anteriormente al mencionar la creación de nuevos espacios turísticos experienciales y de ocio de calidad en los centros urbanos. En este sentido, cumplen con las tendencias de re-invención y tematización con el fin de atraer a nuevos turistas (Gago et al. 2017).

En este sentido, hubiera sido interesante conocer la fecha de la puesta en turismo (Gwiazdzinski, 2009) de las terrazas. Sin embargo, esta información no aparece recogida en las páginas de los hoteles, por lo que se irá ampliando en la fase futura mencionada en la metodología (figura 2) a través de las entrevistas previstas.

En consonancia con estas expectativas del turista o visitante actual, también se mencionan aspectos diferenciales, haciendo por ejemplo hincapié en la arquitectura singular que, como argumentan Della Lucia \& Trunfio (2018), sirve para atraer a nuevos turistas. El diseño diferencial, destacado igualmente por numerosos establecimientos, es otro de los elementos aplicado a las instalaciones (Richards, 2011). 
A todo ello se añadirían referencias a la decoración y la experiencia gastronómica, otro elemento esencial del turismo experiencial (Castillo-Canalejo et al., 2020), sin dejar de lado la obligada referencia a los cocktail de calidad que suelen destacar en las imágenes promocionales. De esta manera, las terrazas de los hoteles aparecen como espacios innovadores, exclusivos y como remansos de paz en la ciudad, repitiéndose calificativos como oasis (Room Mate Óscar, Barceló Forus, The Principal, Mercure Santo Domingo, Gymage Terrace) o refugio (Bless Hotel) en varias de ellas. Son éstas referencias al turismo emocional (García, 2018) que consigue capturar al turista experiencial (Gândara et al., 2011).

Sin embargo, y en consonancia de lo que se ha comentado anteriormente, el reclamo principal, y el que mejor satisface a la expectativa, es el paisaje, las vistas que son puestas en valor en todas y cada una de las terrazas y que constituyen una vivencia diferencial (Rivera, 2013). Tal como mencionan Babinger \& Serrano (2020), se mencionan las vistas a secas (Hyatt, NH Collection Gran Via, Vincci The Mint, Principal, Aloft); las increíbles o espectaculares vistas $360^{\circ}$ de la ciudad (Óscar, Dear Hotel, Círculo de Bellas Artes, My Way, Hotel NH Collection Gran Vía, Riu Plaza de España); vistas perfectas (Óscar); únicas (Urban); magníficas (H10 Puerta de Alcalá); maravillosas (Imagine, Índigo); preciosas (Riu Plaza España); icónicas (Bless); exclusivas y espectaculares (Meliá Fénix, Dear, Bless). También se mencionan la vista panorámica (NH Collection Suecia H10 Puerta de Alcalá); la panorámica espectacular o exclusiva (ME Reina Victoria, Exe Moncloa) o las fabulosas panorámicas (VP Plaza de España). Todos ellos calificativos que hacen referencia a las experiencias que se venden a los turistas (Vogeler \& Hernández, 2002; Rivera, 2013).

Finalmente destacan otros dos aspectos, que son, por un lado, la referencia al atardecer o las puestas del sol sobre la ciudad (Las Letras, The Hat, Dear, Mercure Santo Domingo, H10 Puerta de Alcalá, My Way), lo que se relaciona perfectamente con el turismo nocturno (Gwiazdzinski, 2009; Giordano et al., 2018) sobre el cual se ha hecho referencia anteriormente y que aparecía recogido en la estrategia de la ciudad de Madrid (Ayuntamiento de Madrid, 2014). Por otro lado, hay referencias al cielo en el sentido de ser una ventana al mismo (Exe Moncloa); de alcanzarlo (Óscar, Índigo); de tocarlo (Emperador) o, más castizo, con la clásica mención "de Madrid al cielo" (Óscar, The Hat).

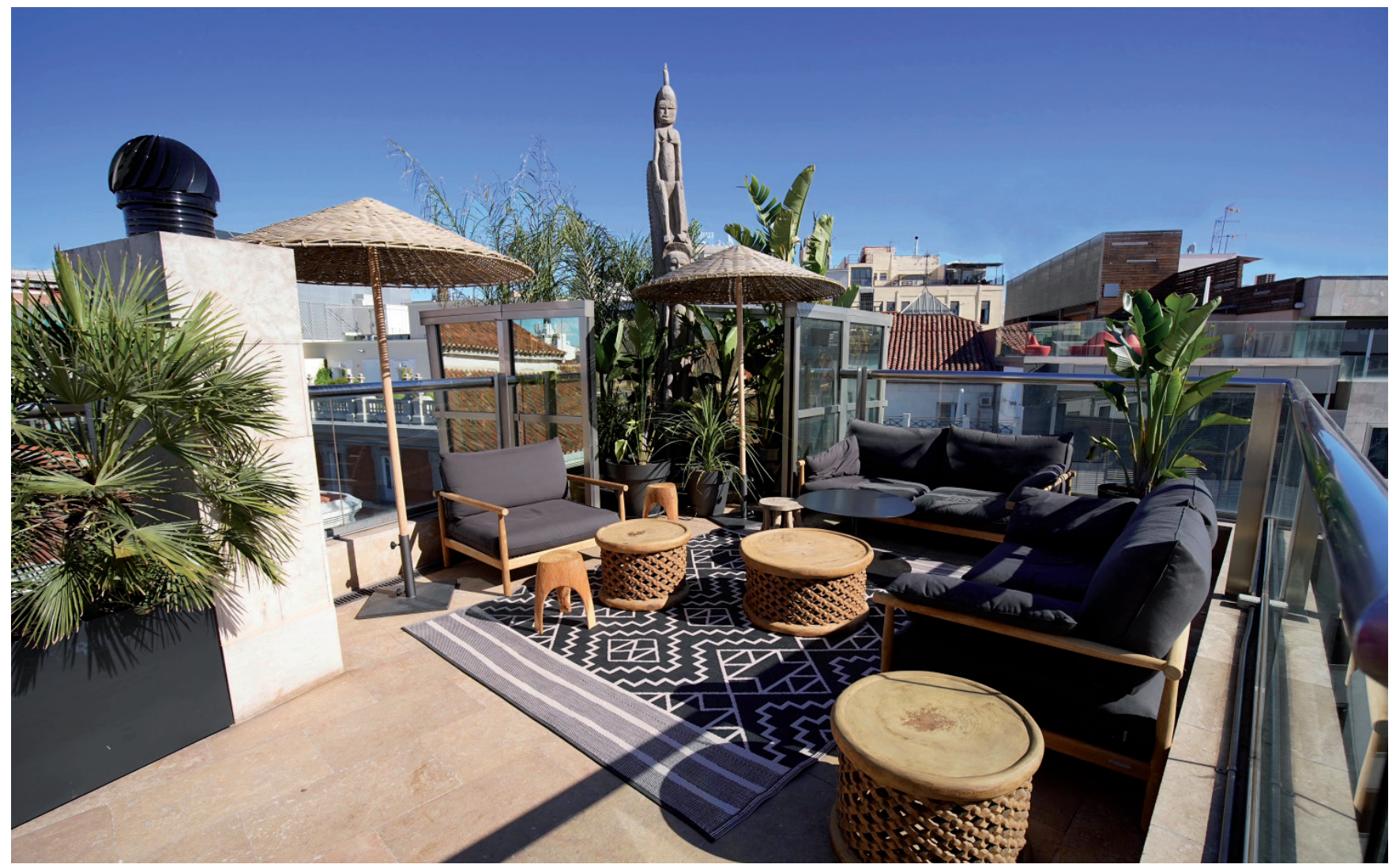

Figura 3. Fotografía de la terraza del hotel Urban $5^{*}$ GL. Fuente: Cedida por la dirección del hotel Urban 5*GL. 
Figura 4. Fotografía de la terraza del hotel Room Mate Óscar. Fuente: Ayuntamiento de Madrid a través de Diario de Madrid bajo licencia Creative Commons CC BY 4.0.

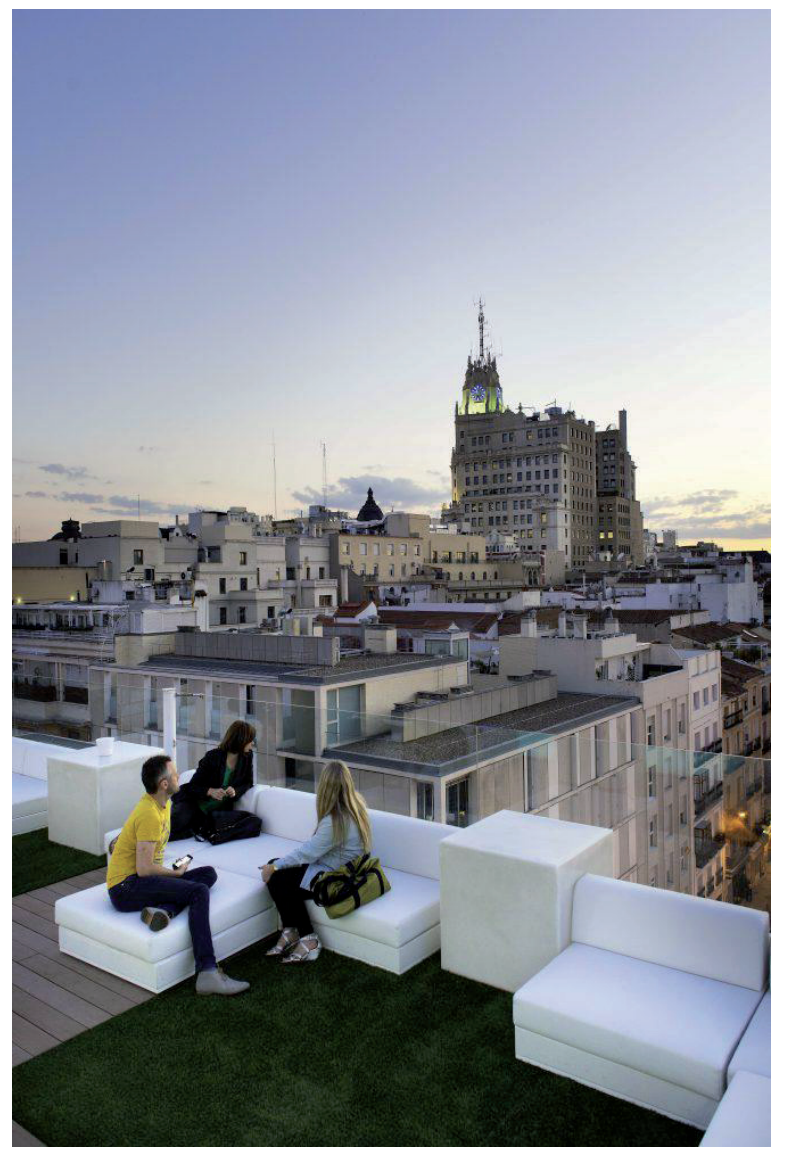

\subsection{Distribución de las terrazas en la ciudad de Madrid}

Una vez comprobado que las terrazas en altura, en especial las de los hoteles, se enmarcan efectivamente en la aparición y promoción de nuevos espacios turísticos experienciales y de ocio en la ciudad, se ha prestado especial atención a la distribución de las mismas en la ciudad de Madrid. Cuando se observa el mapa de la localización de las terrazas en altura en el conjunto del término municipal de la ciudad que se han abierto al turismo (mapa 1), es fácil comprobar cómo se da una concentración exclusiva en la almendra central.

Incluso dentro de la misma se pueden vislumbrar grandes diferencias. Más de tres cuartas partes de las terrazas se ubican en el Distrito Centro (31), muy por delante de otros distritos como Salamanca (5), Retiro (2), Chamberí (1), Chamartín (1) o Tetuán (1).

Esta distribución queda reflejada perfectamente en el mapa de distribución de las terrazas en el centro de Madrid, en la que la concentración en el Distrito Centro es evidente. Incluso la distribución de las terrazas en distritos limítrofes guarda una relación topológica con el centro, como se puede vislumbrar en la figura 5.

Finalmente, la distribución de las terrazas en este Distrito Centro tampoco es aleatoria y sigue un patrón que queda al descubierto cuando se superpone el mapa de la localización de las terrazas con el callejero o, como en este caso, con una imagen de satélite del centro de Madrid (mapa 2).

En este mapa se puede ver con claridad cómo las terrazas se concentran en las áreas más centrales y turísticas de la ciudad, singularmente a lo largo de la Gran Vía, que se comentará más adelante. Además de la Gran Vía, aparece la calle Alcalá como eje secundario, acompañada por hoteles algo más dispersos, aunque relacionados con ambos ejes como al sur de la Plaza Mayor (The Hat), en la Plaza Santa Ana (ME Reina Victoria), frente al Congreso de los Diputados (Urban) o en la Plaza Pedro Zerolo en Chueca (Óscar).

En este sentido, la focalización de las terrazas hoteleras cobra una mayor trascendencia, ya que aquellas terrazas en altura más alejadas del centro no se ubican en hoteles, sino en restaurantes (El Viajero en La Latina), hostales (Bastardo en Tribunal) o mercados (Mercado de San Antón en Chueca y la Azotea Forus Barceló 
del mercado del mismo nombre). Aunque haya otras terrazas, como Cibeles, Casino u Círculo de Bellas Artes, la gran mayoría de las terrazas se ubican en hoteles, que, como se ha comentado con anterioridad, las han convertido en su seña de identidad (Della Lucia \& Trunfio, 2018; Richards, 2011).

Esta constatación da lugar a lecturas diversas. Por un lado, queda claro que la irrupción de las terrazas no puede ser entendida sin la relación con el turismo y el ocio, especialmente relacionados con la experiencia turística. Tal como hemos señalado, no se ubican aleatoriamente en la ciudad, sino que muestran una concentración espacial muy marcada en la almendra central, en el distrito central y, con mayor énfasis, a lo largo de la Gran Vía y sus inmediaciones.

En clara relación con esto, el mapa 3, realizada por García et al. (2017) muestra la especialización hotelera en los barrios de Madrid, observándose como mayoritariamente se da en el distrito Centro, destacando nuevamente la Gran Vía y aledaños en consonancia con lo descrito anteriormente. ${ }^{1}$

No es casualidad que los nuevos o reformados hoteles de lujo, a los que hicimos referencia anteriormente, se ubiquen en este mismo Distrito Centro de la ciudad de Madrid, epicentro del turismo y de las terrazas como renovada oferta de turismo experiencial y de calidad.

Un aspecto importante a recalcar es que los hoteles, en esta reinvención de sus terrazas (Gago et al., 2017), las han abierto a todo el público en una estrategia de puesta a disposición del turismo (Gwiazdzinski, 2009). Lo que se diferencia de su uso tradicionalmente reservado exclusivamente a sus huéspedes. De esta manera, las terrazas hoteleras se han convertido en una oferta de calidad tanto para el turismo nacional e internacional, como para el ocio local de los residentes (Fernández, 2010). Una combinación de turismo y de ocio que se enmarca en la línea del turismo experiencial para que el turista pueda participar en la actividad de los residentes y ser protagonista de su propia experiencia turística (García, 2018). Mientras que éstos, a su vez, pueden disfrutar de su propia ciudad en una exclusiva combinación de (co-)creación de nuevos espacios turísticos (García, 2018; Richards, 2020).

Mapa 1. Mapa de localización de terrazas en altura en el centro de Madrid. Fuente: Elaboración propia.

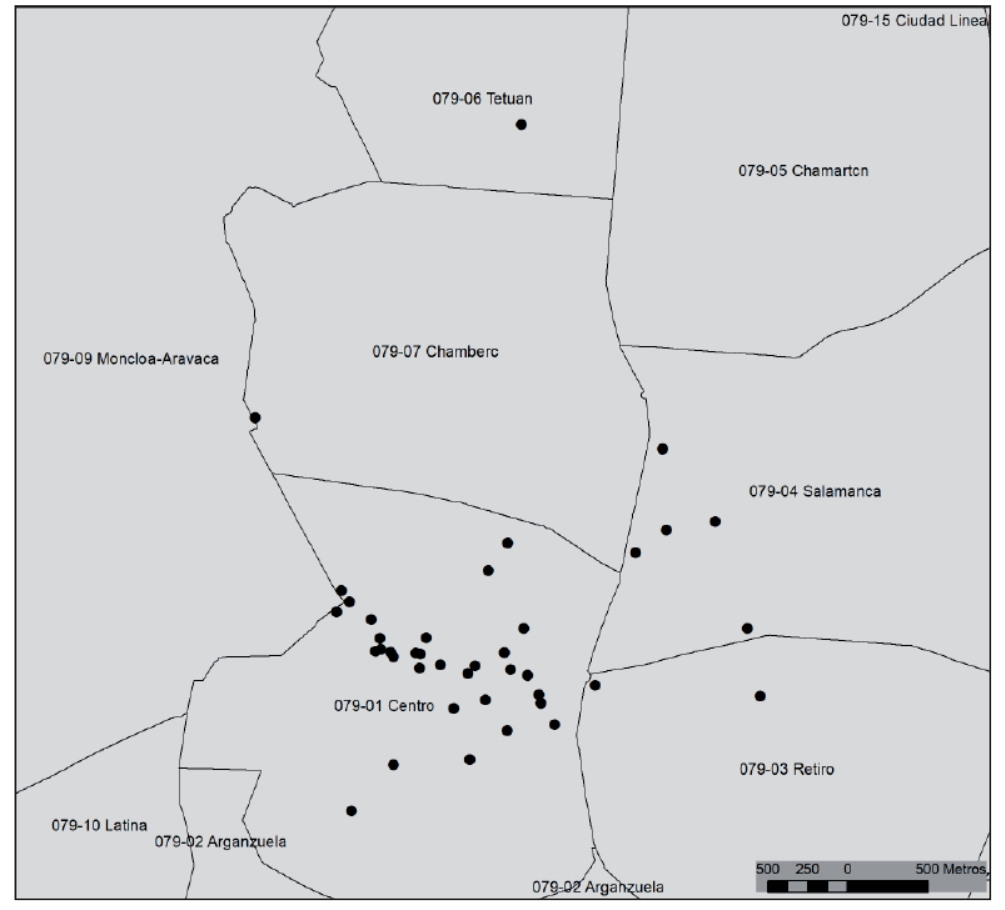

1. Esta cartografía fue elaborada con datos del Censo de Locales por actividad económica publicado por el Ayuntamiento de Madrid, aplicando un cociente de Sargent-Florence, a partir de la siguiente fórmula: $\mathrm{CL}=(\mathrm{Eij} / \mathrm{Ei}) /(\mathrm{Ej} / \mathrm{Et})$, donde: $\mathrm{CL}=\mathrm{Cociente}$ de localización; $\mathrm{Eij}=$ total de hoteles en cada uno de los barrios considerados; $\mathrm{Ei}=\mathrm{n}^{\circ}$ de establecimientos totales con actividad económica en cada uno de los barrios considerados; $\mathrm{Ej}=$ total hoteles en Madrid; $\mathrm{Et}=$ total de establecimientos con actividad económica en la ciudad de Madrid.

A través de este cociente se mide el grado de especialización en una actividad concreta en una unidad espacial determinada, en este caso el barrio. Hay especialización en la actividad considerada con cifras por encima de 1. La especialización ya es considerable con cifras por encima de 1,5. 


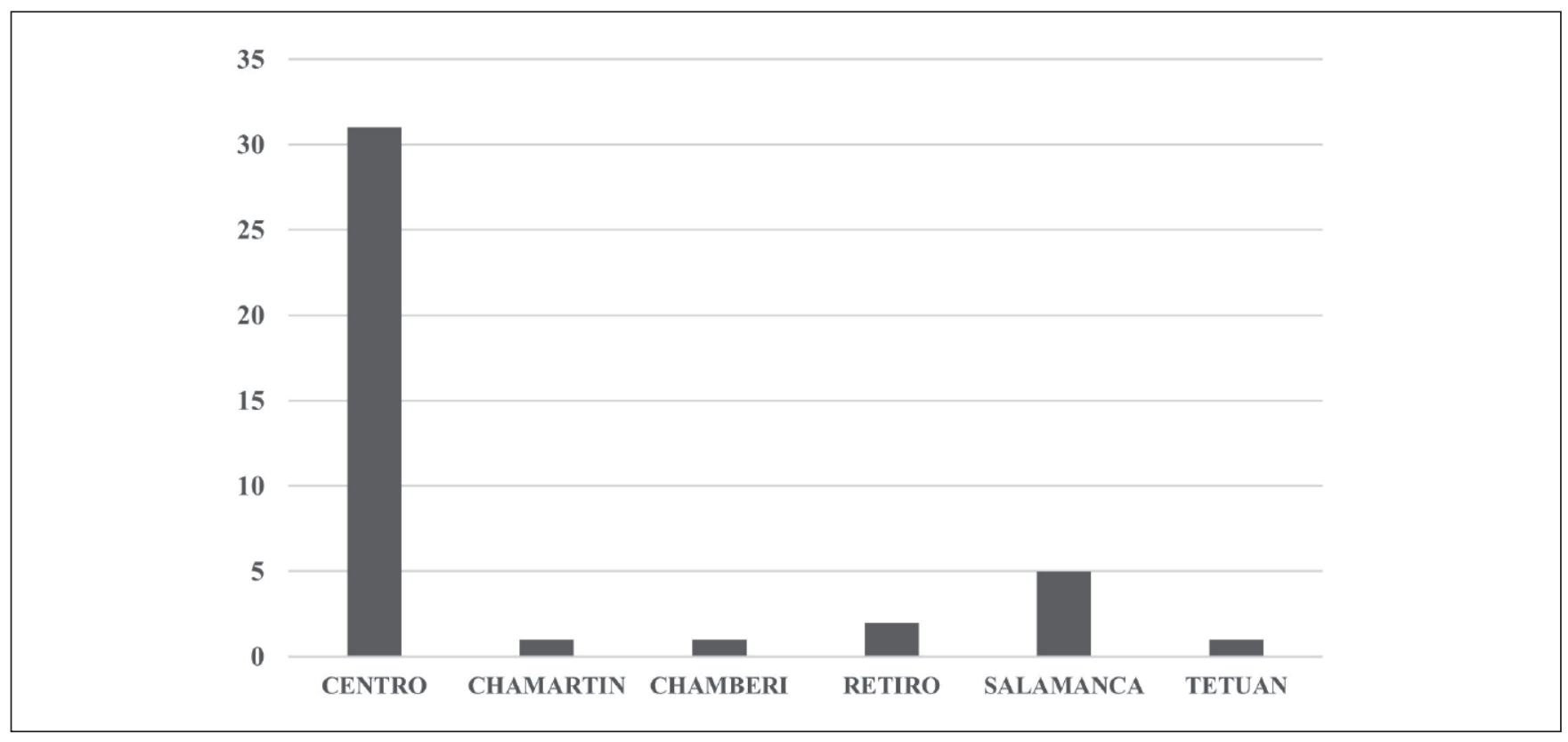

Figura 5. Número de terrazas en altura por distritos de la ciudad de Madrid. Fuente: Elaboración propia.

Mapa 2. Localización de las Terrazas en el Distrito Centro de la ciudad de Madrid. Fuente: Elaboración propia.

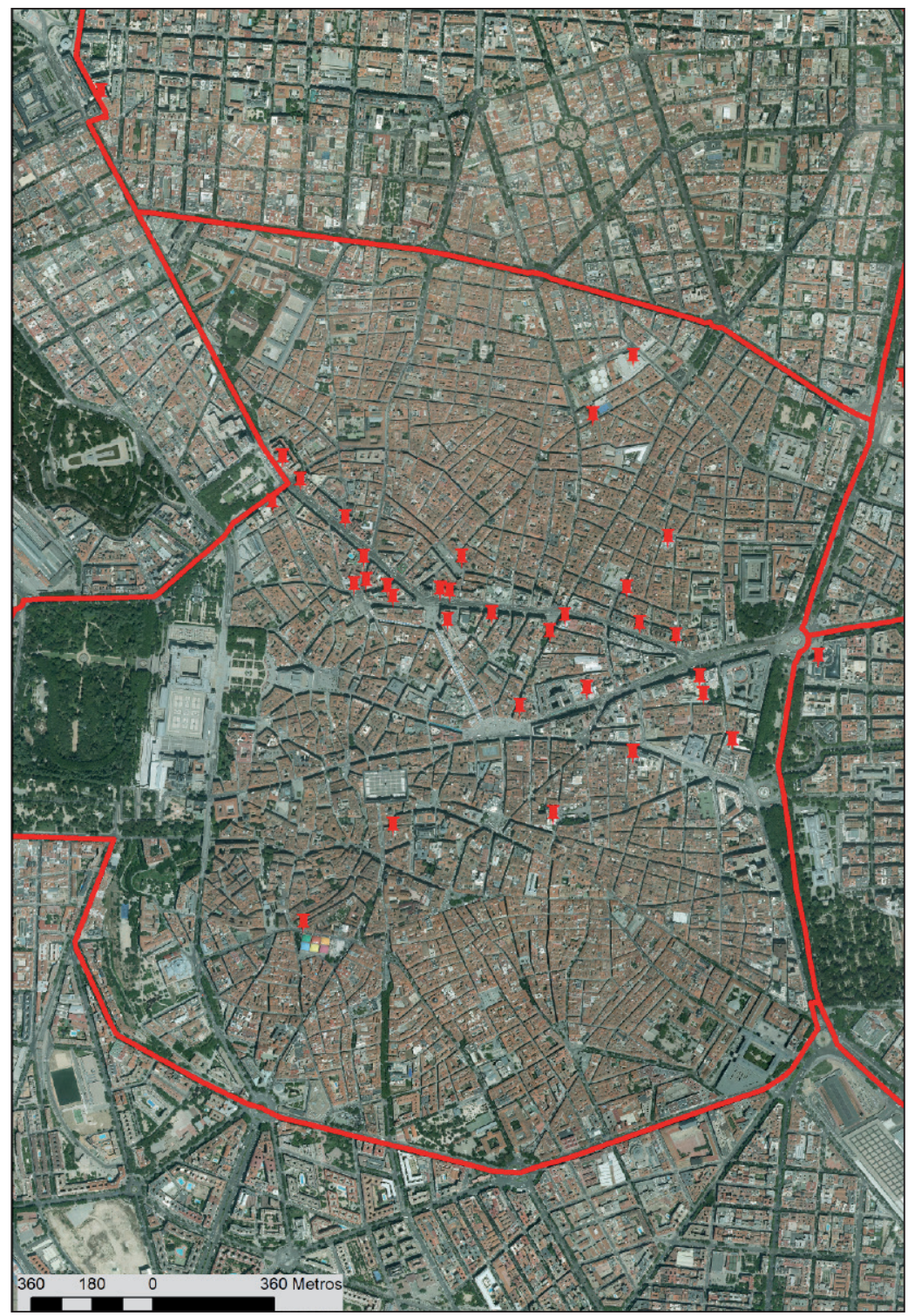




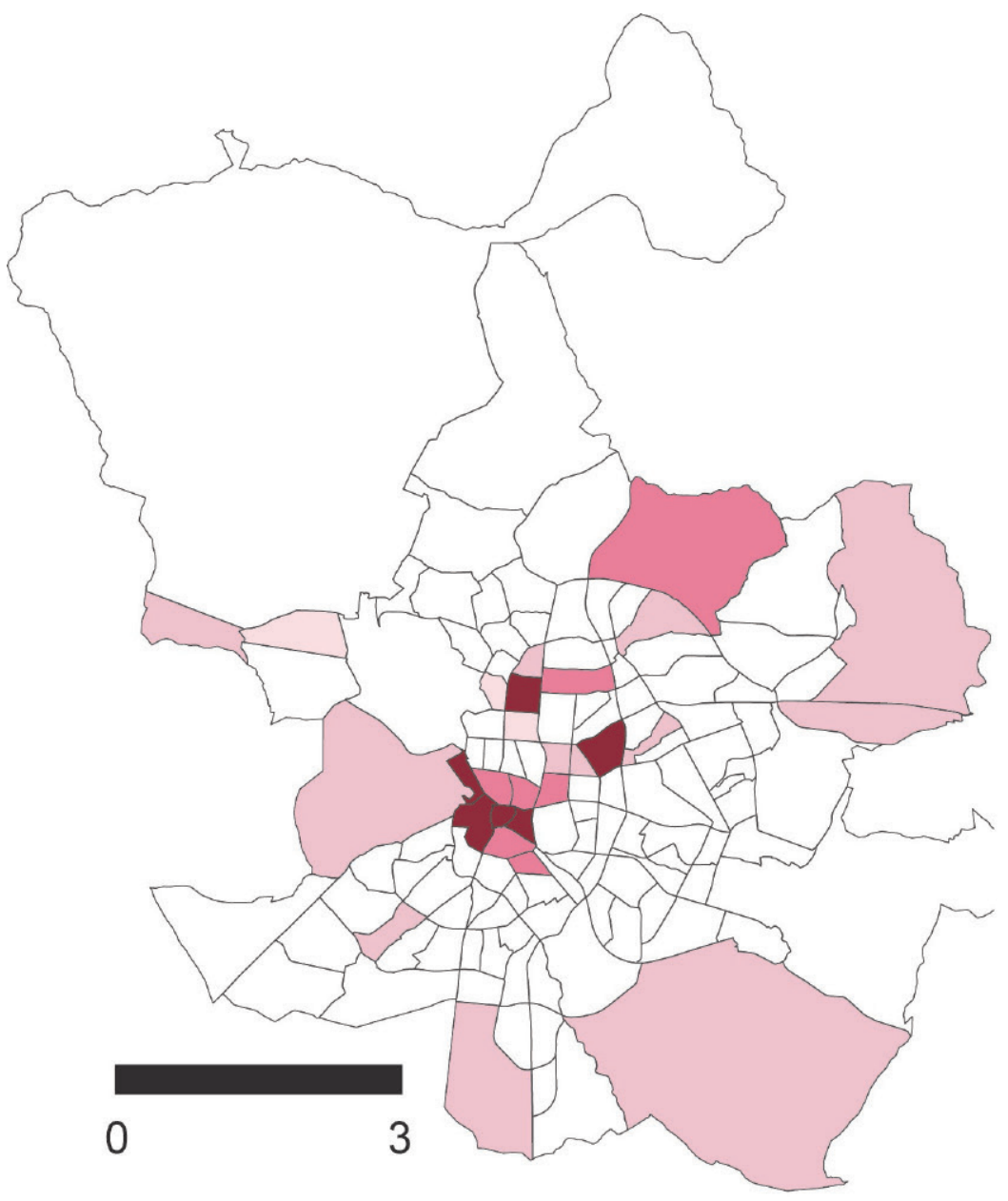

Considerable $(1,5$ a 2$)$

Alto (2 a 5$)$

Muy alto $\mathrm{A}(5$ a 15$)$

Sobresaliente (sup. a 15)

Mapa 3. Especialización hotelera en los barrios de Madrid. Fuente: García, Díez y Córdoba (2017).

\section{CONCLUSIONES}

Las terrazas incorporadas a la oferta turística experiencial y de ocio de calidad en la ciudad de Madrid son fruto de una estrategia encabezada tanto por el Ayuntamiento de Madrid, como de los hoteles de lujo o alta gama. Estas terrazas son, frecuentemente, de reciente creación y suponen la remodelación o la reinvención de espacios que previamente no se habían aprovechado de la misma manera. La apertura de las terrazas en altura, especialmente las hoteleras, supone la combinación del turismo de visitantes y del ocio de los habitantes de la ciudad, una vez que se han abierto a todos los públicos, sin limitaciones. En este sentido podemos hablar de una diversificación de la oferta turística experiencial y de ocio en Madrid, en especial la relacionada con la vida nocturna como se ha mencionado anteriormente.

Las terrazas hoteleras constituyen una oferta turística y de ocio relativamente nueva, ya que anteriormente su uso estaba limitado a los inquilinos de los mismos. A partir de la posibilidad de ofertar experiencias turísticas únicas, relacionadas con el consumo del paisaje que se puede disfrutar de las mismas, es cuando cobran un significado especial.

En este sentido cabe resaltar que esta oferta experiencial no se limita a los turistas, sino que se abre de la misma manera al ocio local de los residentes. Una combinación de turismo y de ocio, de consumo del paisaje urbano, que se enmarca en la línea del turismo experiencial para que el turista pueda participar en la actividad de los residentes, mientras que éstos, a su vez, pueden disfrutar de su propia ciudad en una exclusiva combinación de ocio y turismo (Babinger \& Serrano, 2020).

En este trabajo se ha podido observar como la distribución y ubicación de las terrazas en altura y, singularmente la de los hoteles, responden a un patrón clásico, abarcando las áreas más turísticas de la ciudad 
de Madrid, lo que indica una clara relación entre unas y otras. De esta manera, no es de extrañar que la distribución de las terrazas hoteleras en altura de la ciudad de Madrid responde a patrones clásicos con una concentración en el centro turístico de la ciudad. Concretamente, se distribuyen preponderantemente a lo largo de la Gran Vía y sus inmediaciones, en los que se pueden obtener las mejores vistas de la ciudad. Aquellas, que ofertan la mejor experiencia de consumo de paisaje de la ciudad de Madrid desde las terrazas hoteleras para turistas, visitantes y población local.

Esta constatación da lugar a lecturas diversas. Por un lado, queda claro que la irrupción de las terrazas no puede ser entendida sin la relación con el turismo y el ocio, especialmente relacionados con la experiencia turística. No se ubican aleatoriamente en la ciudad, sino que muestran una concentración espacial muy marcada en la almendra central, en el distrito central y, con mayor énfasis, a lo largo de la Gran Vía y sus inmediaciones.

Por otro lado, esta concentración no se corresponde con los intentos recientes de diversificar el turismo territorialmente por la ciudad con la apertura de nuevos centros secundarios como, por ejemplo, Madrid Río. La distribución de las terrazas responde a la de los hoteles previamente existentes, por lo que refuerzan la centralidad de la actividad turística y de ocio en las áreas tradicionales. Por lo tanto, podemos decir que la tendencia actual de las terrazas en altura se enmarca en la apuesta por la experiencia turística completa, además de ser una nueva oferta turística y de ocio para visitantes y residentes.

Para terminar, queda por comentar que la situación debida a la irrupción de la pandemia ligada al virus Covid-19 ha limitado la fase final de la investigación. El trabajo de campo se ha visto restringido por la imposibilidad de acceder a algunos espacios que se habían previsto.

De la misma manera, la posibilidad de hacer entrevistas con los responsables de las terrazas hoteleras, algunas ya organizadas y agendadas, se ha visto limitada, por lo que se ha preferido dejar esta posibilidad para futuros avances de la investigación en marcha.

En el futuro más inmediato se propone retomar la investigación con estos temas pendientes y enriquecerla con otros que nos parecen interesantes para profundizar en la misma. Por un lado, acometer el análisis de los comentarios que dejan los usuarios en las redes sociales y en plataformas como TripAdvisor para ver si los turistas y los residentes presentan similitudes o diferencias a la vez de constatar si las terrazas realmente satisfacen las expectativas como se ha comentado.

Además, es nuestro propósito ampliar la presente investigación a otras ciudades que presentan la misma tendencia con la aparición de terrazas como oferta de calidad en los centros urbanos. Sevilla, Málaga - Barcelona, entre otros, también han visto la (re)apertura de terrazas hoteleras con fines turísticos y de ocio, y quedaría por verificar si responden a los mismos patrones que hemos descubierto en la ciudad de Madrid.

Finalmente, la situación actual y futura, marcada por la crisis provocada por el Covid-19, permite augurar una mayor demanda de las terrazas al permitir la aglomeración de personas al aire libre. La demanda de este tipo de espacios está creciendo mientras que las terrazas permiten satisfacer la misma sin tener que abandonar el centro turístico de la ciudad para su disfrute.

Aunque pueda parecer una situación puntual, auguramos que la mayor frecuentación de las terrazas como espacios abiertos, constatada por el responsable de uno de los hoteles, permanecerá en el tiempo. La experiencia turística y paisajística que ofrecen las terrazas en altura se enmarca perfectamente en las nuevas tendencias de los visitantes actuales y futuros.

\section{Financiación}

El presente artículo se enmarca en el Proyecto CSO2016-75722-R Ciudades para el turismo: cambios y permanencias en contextos de competitividad global dirigido por los profesores Juan Córdoba Ordóñez y Cándida Gago García. 


\section{Declaración responsable y conflicto de intereses}

Los/as autores/as declaran que no existe ningún conflicto de interés con relación a la publicación de este artículo. Los/as autores/as manifiestan que el presente artículo es fruto del trabajo colaborativo y ambos/as han participado de forma equilibrada en cada una de las partes.

\section{REFERENCIAS}

Ashworth, G. J. (1989). Urban Tourism: An Imbalance in Attention. En C. Cooper (ed.) Progress in Tourism Recreation and Hospitality Management, vol. 1, (pp. 33-54).

Ayuntamiento de Madrid (2014). Plan Estratégico de Turismo 2015-2019. Madrid Destino. https://www.madrid-destino. com/sites/default/files/2018-05/Plan\%20Estrat\%C3\%A9gico\%20Turismo\%202015-2019_Madrid\%20Destino.pdf

Ayuntamiento de Madrid (2019). Anuario de Turismo Madrid 2019. Área de Turismo de Madrid Destino. https://www.madrid-destino.com/sites/default/files/2020-03/Anuario\%20Turismo\%20Madrid\%202019_interactivo.pdf

Babinger, F. \& Serrano, M. (2020). Turistificación como vector de nuevos recursos de calidad: terrazas hoteleras como oferta turística. En G.X. Pons, A. Blanco-Romero, R. Navalón-García, L. Troitiño-Torralba \& M. Blázquez-Salom (eds.) Sostenibilidad Turística: overtourism vs undertourism. So Mon. Soc. Hist. Nat. Balears, 31 (pp. 147-160). Palma (Illes Balears). http://ibdigital.uib.es/greenstone/sites/localsite/collect/monografiesHistoriaNatural/index/assoc/Monograf/iesSHNB_/2020vol0/31p147.dir/MonografiesSHNB_2020vol031p147.pdf

Castillo-Canalejo, A. M., Sánchez-Cañizares, S. M., Santos-Roldán, L. \& Muñoz-Fernández, G. A. (2020). Food Markets: A Motivation-Based. Segmentation of Tourists. International Journal of Environmental Research and Public Health, 17, 2312. https://doi.org/10.3390/ijerph17072312

Comunidad de Madrid (2015). Estrategia de Turismo 2016-2019. Comunidad de Madrid. http://www.madrid.org/cs/ Satellite?blobcol=urldata\&blobheader=application\%2Fpdf\&blobheadername1=Content-Disposition\&blobheadervalue1=filename\%3DEstrategiaTurismoCAM_vDEF.PDF\&blobkey=id\&blobtable=MungoBlobs\&blobwhe$r e=1352913096654 \&$ ssbinary=true

Córdoba Ordóñez, J. (2009). Turismo, desarrollo y disneyzación: ¿una cuestión de recursos o de ingenio? Investigaciones Geográficas, 70, 33-54. http://www.scielo.org.mx/pdf/igeo/n70/n70a3.pdf

Córdoba, J. \& Gago, C. (2018). Ciudades para el turismo: nuevas estrategias para el desarrollo regional en tiempos de crisis. En J. A. Márquez Domínguez \& R. Jordá Borrell (eds.) Ciencia regional y Andalucía a partir de la visión del geógrafo Gabriel Marco Cano García: un homenaje a su vida y obra (pp. 713-732). Editorial Universidad de Sevilla. https:// dx.doi.org/10.12795/9788447221523

Da Rocha Neto, J. M. \& Furtado, E. M. (2018). Os "novos" velhos portos: espaços de metamorfose para o capital imobiliário e para o turismo. Cadernos de Geografia, 37, 43-54. https://doi.org/10.14195/0871-1623_37_4

Della Lucia, M. \& Trunfio, M. (2018). The role of the private actor in cultural regeneration: Hybridizing cultural heritage with creativity in the city. Cities, 82, 35-44. https://doi.org/10.1016/j.cities.2018.05.003

De Rojas, C. \& Camarero, C. (2008). Visitors experience, mood and satisfaction in a heritage context: Evidence from an interpretation center. Tourism management, 29, 525-537. https://doi.org/10.1016/j.tourman.2007.06.004

Díaz Soria, I. \& Llurdés Coit, J. C. (2013). Reflexiones sobre el turismo de proximidad como una estrategia para el desarroIlo local. Cuadernos de Turismo, 32, 65-88. https://revistas.um.es/turismo/article/view/177421

Diaz-Soria, I. (2017) Being a tourist as a chosen experience in a proximity destination, Tourism Geographies, 19 (1), 96-117. https://doi.org/10.1080/14616688.2016.1214976

Fernández Alvariño, C. (2010). Sociedad postmoderna y turismo. Nuevas tendencias de ocio post-turismo. X Congreso Español de Sociología (pp. 21-34). Pamplona.

Gago García, C., Díez Pisonero, R. \& Córdoba Ordóñez, J. (2017). Relaciones entre ocio-consumo, turismo y gentrificación en los barrios de Madrid. En Naturaleza, Ciudad y Territorio en un mundo Global, Actas del XXV Congreso de la AGE. Madrid. https://doi.org/10.15366/ntc.2017

Gago García, C. \& Díez-Pisonero, R. (2020). Bohemios, hípsters, alternativos, étnicos, todos "modernos": barrios de Madrid y Barcelona y su contribución a las dinámicas urbanas recientes. En Comité Español de la Unión Geográfica 
Internacional (UGI). Aportación Española al $34^{\circ}$ Congreso de la UGI. Estambul 2020: España, puente entre continentes. Centro Nacional de Información Geográfica, Madrid, España. https://doi.org/10.7419/162.10.2020

Gago García, C., Córdoba Ordóñez, J. \& Díez Pisonero, R (2021). Imagen territorial y servicios para el turismo. Los casos de Malasaña y Lavapiés (Madrid). En C. Gago, J. Córdoba, M. P. Alonso, R. M. Jordá \&J. Ventura (eds.) Una perspectiva integrada: Aportaciones desde las geografías Económica, regional y de los servicios para la cohesión y la competitividad territorial.

García Henche, B. (2017). Los mercados de abastos y su comercialización como producto de turismo de experiencias. El caso de Madrid. Cuadernos de Turismo, 39, 167-189. http://dx.doi.org/10.6018/turismo.39.290491

García Henche, B. \& Salvaj Carrera, E. (2017). Asociacionismo, redes y marketing en la transformación hacia el turismo experiencial. El caso del barrio de las letras. Cuadernos de Turismo, 40, 315-338. http://dx.doi.org/10.6018/turismo.40.309731

García Henche, B. (2018). Urban experiential tourism marketing. Use of social med.ia as communication tools by the food markets of Madrid. Journal of Tourism Analysis: Revista de Análisis Turístico, 25, 1, 2-22. https://doi.org/10.1108/ JTA-01-2018-0002

Gilmore, H. J. \& Pine B. J. (2002). The Experience IS the Marketing. Brown Herron Publishing.

Giordano, E., Nofre Mateu, J. \& Crozat, D. (2018). La touristification de la vie nocturne: une nouvelle frontière pour la recherche sur la nuit urbaine. Cybergeo-European Journal of Geography, UNSP 866. https://doi.org/10.4000/cybergeo.29473

Gwiazdzinski L. (2009). Pour une mise en tourisme des nuits urbaines. Cahier Espaces, 103, 44-56. https://halshs.archives-ouvertes.fr/halshs-00551117

Hannigan, J. (2005). Fantasy city. Routledge. https://doi.org/10.4324/9780203984628

Hosteltur (2020, 5 de marzo). https://www.hosteltur.com/113130_turismo-urbano-vive-boom-escala-global.html

IEPPO, IE Premium and Prestige Observatory (2017). High Value City Travel Report 2017. IEPPO. https://observatoriodelmercadopremium.ie.edu/high-value-city-travel-report-2017/

Igoe, J. (2010). The spectacle of nature in the global economy of appearances: Anthropological engagements with the spectacular mediations of transnational conservation. Critique of Anthropology, 30-74, 375-397. https://doi.org/10.1177/0308275X10372468

INE, Instituto Nacional de Estadística (2019). Encuesta de Ocupación hotelera, 2019 y años anteriores. Madrid: INE. https://www.ine.es/dyngs/INEbase/es/operacion.htm?c=Estadistica_C\&cid=1254736177015\&menu=resultados\&i$\mathrm{dp}=1254735576863 \# !$ tabs-1254736195376

Lefebvre, H. \& Martínez Lorea, I. (2013). La producción del espacio. Capitán Swing.

Liu, D. \& Dewancker, B. J. (2018). A comparative study on user satisfaction with an observatory between Sarakura and Takato Mountain, Japan. Sustainable development and planning IX, Collection: WIT Transactions on Ecology and the Environment, 226, 793-800. https://www.witpress.com/elibrary/wit-transactions-on-ecology-and-the-environment/226/36342

Mansvelt, J. (2008). Geographies of consumption: citizenship, space and practice. Progress in Human Geography, 32 (1), 105-117. https://doi.org/10.1177/0309132507080623

Miles, S. (2012). The neoliberal city and the pro-active complicity of the citizen consumer. Journal of Consumer Culture, 12(2), 216-230. https://doi.org/10.1177/1469540512446881

Murphy, C. \& Boyle, E. (2006). Testing a conceptual model of cultural tourism development in the post- industrial city: a case study of Glasgow. Tourism and Hospitality Research, 6 (2), 111-128. https://doi.org/10.1057/palgrave.thr.6040050

Nogué i Font. (1989). Paisaje y turismo. Estudios Turísticos, 103, 35-46. https://turismo.janium.net/janium/Objetos/REVISTAS_ESTUDIOS_TURISTICOS/55237.pdf

Pine, B. J. \& Gilmore, J. H (1999). The experience economy: Work is Theater \& Every Business a Stage. Harvard Business School Press.

Quaglieri Domínguez, A. \& Russo, P. (2010). Paisajes urbanos en la época post-Turística. Propuesta de un marco analítico. Scripta Nova Revista Electrónica de Geografía y Ciencias Sociales, Vol. XIV, núm. 323, 10 de mayo de 2010. http://www. ub.edu/geocrit/sn/sn-323.htm

Richards, G. (2004). ¿Nuevos caminos para el turismo cultural? En Interacció 2004, (pp. 1-15), Centro de Estudios Culturales CERC, Barcelona. www.diba.es/cerc/arxinterac04/arcem1/richards/dipbarcelona 
Richards, G. (2011). Creativity and tourism: The state of the art. Annals of Tourism Research, 38(4), 1225-1253. https://doi. org/10.1016/j.annals.2011.07.008

Richards, G. (2020). Designing creative places: The role of creative tourism. Annals of Tourism Research, 85, November 2020, 102922. https://doi.org/10.1016/j.annals.2020.102922

Rivera Mateos, M. (2013). El turismo experiencial como forma de turismo responsable e intercultural. En L. Rodríguez García \& A. R. Roldán Tapia (eds.) Relaciones interculturales en la diversidad (pp. 199-217).

Sassen, S. (1991). The global city. Willey.

Scheyvens, R. (2002). Tourism for development: empowering communities. Prentice-Hall.

Schmitt, B. H. (1999). Experimental Marketing: How to Get Customers to Sense Feel, Think, Act and Relate to Your Company and Brands. Free Press.

Schmitt, B. H. (2003). Consumer Experience Management: A Revolutionary Approach to Connecting with Your Customers. Jhon Willey and Sons.

Serrano, M. \& Babinger, F. (2021). Consumo de paisaje en ciudades turísticas: el papel de las terrazas hoteleras en la ciudad de Madrid. En C. Gago, J. Córdoba, M. P. Alonso, R. M. Jordá \& J. Ventura (eds.) Una perspectiva integrada: Aportaciones desde las geografías Económica, regional y de los servicios para la cohesión y la competitividad territorial. (pp. 236-245)

Sharpley, R. \& Telfer, D. (2003). Tourism and development: Concepts and issues. Clevedon.

Smith, W. L. (2006) Experiential Tourism around the World and at Home: Definitions and Standards. International Journal of Services and Standards. https://doi.org/10.1504/IJSS.2006.008156

Thrift, N. (1997). Cities without modernity, cities with magic. Scottish Geographical Magazine, 113, 138 -149. https://doi. org/10.1080/00369229718737007

Trivi, N. (2008). El paisaje, del atractivo al fetiche. Un ensayo sobre consumo visual y turismo. PASOS. Revista de Turismo y Patrimonio Cultural, 16 (4), 1131-1141. https://doi.org/10.25145/j.pasos.2018.16.078

Urry, J. (2002). Consuming places. Routledge. https://doi.org/10.4324/9780203202920

Urry, J. (2010). Consuming the planet to excess. Theory, Culture \& Society, 27 (2-3), 191-212. https://doi. org/10.1177/0263276409355999

Vogeler, C. \& Hernández, C. (2002). El Mercado Turístico: estructura, operaciones y procesos de producción. Centro de Estudios Ramón Areces.

Zukin, S. (1995). The Cultures of Cities. Blackwell. 